\title{
Secure SOA Framework for Multi-Cloud Storage and Computing
}

\author{
Megha Mayreddy \\ M.Tech Student, Dept.of CSE \\ Kallam Haranadha Reddy Institute of Technology \\ Guntur, Andhrapradesh, India
}

\author{
B.Tarakeswara Rao, Ph.D \\ Professor, Dept.of CSE \\ Kallam Haranadha Reddy Institute of Technology \\ Guntur, Andhrapradesh, India
}

\begin{abstract}
Distributed computing is a swearing up and down to technology to encourage advancement of extensive scale, oninterest, adaptable figuring foundations. Anyhow without security implanted into imaginative engineering that backings distributed computing, organizations are setting themselves up for a fall. The pattern of every now and again receiving this engineering by the associations consequently presented new hazard on top of existing danger. Clearly placing everything into a solitary box i.e. into the cloud will just make it simpler for programmer. This paper exhibits a diagram and the investigation of the distributed computing and storage. Additionally incorporate the few security and testing issues, rising application and the future patterns of distributed computing.
\end{abstract}

\section{Keywords}

Integrity, Confidentiality, SOA, IaaS, PaaS, SaaS.

\section{INTRODUCTION}

Cloud processing describes programs and solutions provided within the Internet. These solutions are given from information centres throughout the earth, which collectively are known as the "cloud."That metaphor presents the intangible; however common character of the Web [1].The notion of the "cloud" simplifies the numerous system associations and pc techniques associated with on the web services. Actually, several system images utilize the picture of a cloud to signify the Internet. That symbolizes the Internet's wide achieve, while simplifying their complexity. Any individual by having a Net connection may entry the cloud and the solutions it provides. Because these solutions in many cases are related, consumers may reveal data between numerous techniques and with different users $[1,2]$.

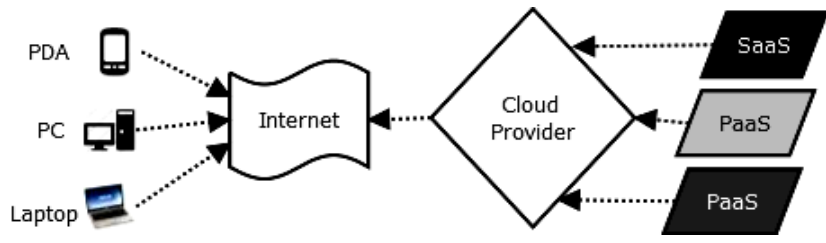

Figure. 1 Cloud Computing

\section{ARCHICTECTURE OF CLOUD COMPUTING}

In this segment, we introduce a top-level construction modelling of distributed computing that delineates different cloud administration conveyance models. Distributed

\section{CLOUD SER VICE DEPLOYMENT AND CONSUMPTION MODELS}

Cloud Service Deployment and Consumption Models Despite the conveyance model used (Saas, Paas, Iaas) there are four essential routes in which cloud administrations are conveyed computing improves cooperation, deftness, scale, accessibility and gives the potential for expense diminishment through streamlined and productive figuring. All the more particularly, cloud portrays the utilization of an accumulation of disseminated administrations, applications, data and foundation included pools of process, system, data and capacity assets (CSA Security Guidance, 2009). These segments can be quickly coordinated, provisioned, actualized and decommissioned utilizing an on demand utility-like model of portion and utilization. Cloud administrations are frequently, however not generally, 3 used in conjunction with an empowered by virtualization advances to give dynamic combination, provisioning, arrangement, versatility and scale. While the very meaning of cloud proposes the decoupling of assets from the physical natural inclination to furthermore area of the base that conveys them, numerous portrayals of cloud go to one compelling or an alternate by either misrepresenting or falsely restricting the numerous properties of cloud. This is frequently intentionally done trying to swell or minimize its extension. A few illustrations incorporate the recommendations that for a administration to be cloud-based, that the Internet must be utilized as a vehicle, a web program must be utilized as an access modality or that the assets are constantly imparted in a multi-inhabitant environment outside of the "border." What is lost in these definitions is setting. From a building viewpoint, given this absorbed development of innovation, there is much disarray encompassing how cloud is both comparative and unique in relation to existing models and how these likenesses and contrasts may affect the hierarchical, operational and innovative methodologies to cloud appropriation as it identifies with customary system and data security hones. There are the individuals who say cloud is a novel ocean change and specialized upheaval while different recommends it is a regular advancement and blend of innovation, economy and society. The true truth is some place in the middle. There are numerous models accessible today which endeavour to address cloud from the point of view of academicians, planners, engineers, designers, chiefs and even purchasers. The building design that we will concentrate on this section is particularly customized to the special points of view of IT system organization and administration conveyance. Cloud administrations are based upon five foremost qualities that show their connection to, and contrasts from, conventional figuring methodologies (CSA Security Guidance, 2009). These attributes are: (i) Deliberation of Base, (ii) Asset Democratization,(iii) administration arranged structural engineering, (iv) Versatility/Dynamism, (v) Utility Model of Utilization and Assignment.

(CSA Security Guidance, 2009). Cloud integrators can assume an imperative part in deciding the right cloud way for a particular association.

Open Cloud: Public mists are given by an assigned administration supplier and may offer either a Single Tenant (Committed) or Multi-Inhabitant (Imparted) working 
environment with all the profits and usefulness of versatility and the Responsibility/Utility model of Cloud.

The physical framework is by and large possessed by and oversaw by the assigned administration supplier and spotted inside the supplier's server farms (off premises). All clients have the same foundation pool with restricted setup, security securities, and accessibility fluctuations. One of the preferences of an open cloud is that they may be bigger than an undertaking cloud, and thus they give the capacity to scale flawlessly on interest.

Private cloud: Private mists are given by an association or their assigned administrations and offer a single-inhabitant (devoted) working environment with all the profits and usefulness of versatility and responsibility/utility model of cloud. The private mists plan to address concerns on information security and offer more prominent control, which ordinarily needs in an open cloud. There are two variations of private mists: (i) on-reason private mists and (ii) remotely facilitated private mists. The on-reason private mists, additionally known as inside mists are facilitated inside one's own particular server farm. This model gives a more institutionalized procedure and insurance, however is constrained in parts of size and versatility. IT divisions would likewise need to acquire the capital and operational expenses for the physical assets. This is best suited for applications which oblige complete control and configurability of the base and security. As the name infers, the remotely facilitated private mists are facilitated remotely with a cloud supplier in which the supplier.

Crossover cloud: Hybrid mists are a consolidation of open and private cloud offerings that take into account transitive data trade and potentially application similarity and convenience crosswise over unique cloud administration offerings and suppliers using standard or exclusive procedures paying little respect to possession or area. With a cross breed cloud, administration suppliers can use outsider cloud suppliers in a full or halfway way, subsequently expanding the adaptability of figuring. The cross breed cloud model is able of giving on interest, remotely provisioned scale. The capacity to expand a private cloud with the assets of an open cloud can be utilized to deal with any unforeseen surges in workload.

Oversaw cloud: Managed mists are given by an assigned administration, supplier and may offer either a singleoccupant (committed) or multi-inhabitant (imparted) working environment with all the profits and usefulness of flexibility and the responsibility/utility model of cloud. The physical base is claimed by and/or physically placed in the associations' server farms with an augmentation of administration furthermore security control planes controlled by the assigned administration supplier. The thought of open, private, oversaw and cross breed when portraying cloud benefits truly means the attribution of administration and the accessibility of administration to particular purchasers of the Administrations. Outlines Different Gimmicks of the Four Cloud Sending Models. At the point when surveying the effect a specific cloud administration may have on one's security carriage and in general security building design, it is important to order the advantages/asset/benefit inside the setting of not just its area additionally its criticality and business affect as it identifies with administration and security. This implies that a suitable level of danger evaluation is performed before entrusting it to the notions of the cloud (CSA Security Guidance, 2009). Furthermore, it is paramount to comprehend different trade-offs between the different cloud administration models:
- Generally, Saas gives a lot of coordinated peculiarities incorporated straightforwardly with the offering with the slightest measure of extensibility and when all is said in done an abnormal state of security (or at any rate an obligation for security from the administration supplier).

- Paas offers less coordinated peculiarities since it is intended to empower designers to manufacture their own applications on top of the stage, and it is, hence, more extensible than Saas by nature. Nonetheless, this extensibility gimmicks exchange offs on security peculiarities and capacities.

- Iaas gives few, if any, application-like gimmicks, and accommodates tremendous extensibility however by and large less security capacities and functionalities past ensuring the foundation itself, since it expects working frameworks, applications and substance to be overseen and secured by the clients.

In Synopsis, structure security viewpoint, in the three administration models of distributed computing, the lower down the stack the cloud administration supplier stops, the more security capacities and administration the client is in charge of executing and overseeing themes.

\section{CLOUD COMPUTING SECURITY AND PRIVACY ISSUES}

This Area Addresses the centre topic of this section, i.e., the security and protection related difficulties in distributed computing. There are various security issues for distributed computing as it envelops numerous advances including systems, databases, working frameworks, virtualization, asset booking, transaction administration, burden adjusting, concurrency control and memory administration. Thusly, security issues for large portions of these frameworks and advances are appropriate to distributed computing. For sample, the system that interconnects the frameworks in a cloud must be secure. Moreover, virtualization ideal model in distributed computing prompts a few security concerns. For instance, mapping the virtual machines to the physical machines must be done safely. Information security includes scrambling the information and also guaranteeing that suitable approaches are authorized for information imparting. Moreover, asset portion and memory administration calculations must be secure. At long last, information mining methods may be pertinent for malware discovery in the mists - a methodology which is normally received in interruption recognition frameworks (Idss) (Sen \& Sengupta, 2005; Sen et al., 2006b; Sen et al., 2008; Sen, 2010a; Sen, 2010b; Sen 2010c).

As Indicated in the Table 1, there are six particular territories of the distributed computing environment where gear and programming require generous security consideration (Trusted Computing Group's White Paper, 2010). These six zones are: (1) security of information very still, (2) security of information in travel, (3) validation of clients/applications/ forms, (4) hearty partition between information having a place with distinctive clients, (5) cloud lawful and administrative issues, and (6) occurrence reaction.

For securing information very still, Cryptographic encryption components are surely the best alternatives. The hard drive producers are currently delivering scrambling toward oneself drives that execute trusted capacity norms of the trusted registering gathering (Trusted Computing Group's White Paper, 2010). 
These encoding toward oneself drives incorporate encryption equipment with the drive, giving computerized encryption insignificant expense or execution sway. Despite the fact that product encryption can likewise be utilized for securing information, it makes prepare slower and less secure since it might be feasible for an enemy to take the encryption key from the machine without being discovered. Encryption is the best choice for securing information in travel also. Furthermore, verification and honesty assurance systems guarantee that information just goes where the client needs it to go and it is definitely not changed in travel.

Solid confirmation is a compulsory prerequisite for any cloud arrangement. Client confirmation is the essential premise for access control. In the cloud environment, confirmation and access control are more imperative than any other time since the cloud and every last bit of its information are available to anybody over the Internet. The trusted processing bunch's (Tcg's) IF-MAP standard takes into account constant correspondence between a cloud administration supplier and the client about approved clients and other security issues. At the point when a client's access benefit is renounced or reassigned, the client's personality administration framework can inform the cloud supplier progressively so that the client's cloud access can be changed or disavowed inside a short compass of time.

One of the more clear cloud concerns is division between a cloud supplier's clients (who may be contending organizations or even programmers) to keep away from accidental or deliberate access to touchy data. Normally a cloud supplier would utilize virtual machines (Vms) and a hypervisor to divided clients. Innovations are presently accessible that can give noteworthy security enhancements to Vms and virtual system partition. Also, the trusted stage module (TPM) can give equipment based confirmation of hypervisor and VM uprightness and in this manner guarantee solid system partition and security. Lawful and administrative issues are greatly essential in distributed computing that have security suggestions. To confirm that a cloud supplier has solid approaches and practices that address lawful and administrative issues, every client must have its legitimate and administrative specialists review cloud supplier's strategies and practices to guarantee their ampleness.

The issues to be considered in this respect incorporate information security and fare, consistence, reviewing, information maintenance and devastation, and lawful disclosure. In the ranges of information maintenance and erasure, trusted capacity and trusted stage module access procedures can play a key part in restricting access to touchy and basic information. As a major aspect of expecting the surprising, clients need to get ready for the likelihood of cloud supplier security breaks or client mischief. A robotized reaction $o$ at any rate mechanized warning is the best answer for this reason. The IF-MAP (Metadata Access convention) of the trusted figuring gathering (TCG) determination empowers the joining of distinctive security frameworks and gives ongoing notices of episodes and of client misconduct.

\section{SECURITY ISSUES IN CLOUD COMPUTING}

Security in the cloud is attained, to some degree, through outsider controls and certification much like in conventional outsourcing game plans. Yet since there is no regular distributed computing security standard, there are extra difficulties connected with this. Numerous cloud merchants execute their restrictive principles and security innovations, and actualize contrasting security models, which need to be assessed all alone benefits. In a seller cloud model, it is at last down to receiving client associations to guarantee that security in the cloud meets their security polices through necessities gathering supplier hazard appraisals, due constancy, and affirmation exercises (CPNI Security Briefing, 2010). Along these lines, the security difficulties confronted by associations wishing to utilize cloud administrations are not drastically unique in relation to those subject to their own particular in-house oversaw undertakings. The same inner and outer dangers are available and oblige hazard alleviation or danger acknowledgement. In the accompanying, we look at the data security challenges that embracing associations will need to consider, either through confirmation exercises on the seller or open cloud suppliers or straightforwardly, through outlining and executing security control in an exclusive cloud.

Specifically, we analyse the accompanying issues:

- The treats against data resources living in distributed computing situations.

- The sorts of assailants and their ability of assaulting the cloud.

- The security dangers connected with the cloud, and where applicable contemplations of assaults and countermeasures.

- Emerging cloud security dangers.

- Some sample cloud security incidents

\section{Cloud Security Threats}

The Dangers to data resources dwelling in the cloud can fluctuate as indicated by the cloud conveyance models utilized by cloud client associations. There are a few sorts of security dangers to which distributed computing is helpless. Table 1 gives a review of the dangers for cloud clients arranged as indicated by the secrecy, honesty and accessibility (CIA) security model and their significance to each of the cloud administration conveyance model.

Table 1. Security risks on cloud storage and computing

\begin{tabular}{|c|c|}
\hline Thread & Description \\
\hline Confidentiality & \\
\hline $\begin{array}{l}\text { Insider client dangers: } \\
\text { - } \quad \text { Malicious cloud supplier client } \\
\text { - Malicious cloud client } \\
\text { - } \quad \text { Malicious outsider client (Supporting either the cloud } \\
\text { supplier or client associations) }\end{array}$ & $\begin{array}{l}\text { The Risk of insiders getting to client information held inside } \\
\text { the cloud is more noteworthy as each of the conveyance models } \\
\text { can present the requirement for numerous inner } \\
\text { Clients: } \\
\text { Saas - Cloud Client and Supplier Heads }\end{array}$ \\
\hline
\end{tabular}




\begin{tabular}{|c|c|}
\hline & $\begin{array}{l}\text { Paas- Application Engineers and Test Environment } \\
\text { directors } \\
\text { Iaas- Outsider Stage Advisors }\end{array}$ \\
\hline \multicolumn{2}{|l|}{ Outer aggressor dangers: } \\
\hline $\begin{array}{l}\text { - } \\
\text { - } \\
\text { - } \\
\text { Remote fittings assault against the cloud } \\
\text { cloud client associations' endpoint programming and } \\
\text { fittings } \\
\text { - Social building of cloud supplier clients, what's more } \\
\text { cloud client clients. }\end{array}$ & $\begin{array}{l}\text { The risk from outside assailants may be seen to apply more to } \\
\text { open Internet confronting mists, however different types of cloud } \\
\text { conveyance models are influenced by outer aggressors, } \\
\text { especially in private mists where client endpoints can be focused } \\
\text { on. Cloud suppliers with substantial information stores holding } \\
\text { charge card subtle elements, individual data and touchy } \\
\text { government or protected innovation, will be subjected to assaults } \\
\text { from gatherings, with huge assets, endeavouring to recover } \\
\text { information. This incorporates the risk of fittings assault, social } \\
\text { designing and store network assaults by committed aggressors. }\end{array}$ \\
\hline \multicolumn{2}{|l|}{ Information spillage: } \\
\hline $\begin{array}{ll}\text { - } & \text { Failure of security access rights over different areas } \\
\text { - Failure of electronic and physical transport } \\
\text { frameworks for cloud information and } \\
\text { reinforcements }\end{array}$ & $\begin{array}{l}\text { A risk from across the board information spillage among a lot } \\
\text { of people, conceivably contender associations, utilizing the same } \\
\text { cloud supplier could be created by human lapse then again } \\
\text { defective equipment that will prompt data bargain. }\end{array}$ \\
\hline \multicolumn{2}{|l|}{ RESPECTABILITY } \\
\hline \multicolumn{2}{|l|}{ Information Isolation } \\
\hline $\begin{array}{ll}\text { - Incorrectly characterized security edges } \\
\text { - Incorrect setup of virtual machines furthermore } \\
\text { hypervisors }\end{array}$ & $\begin{array}{l}\text { The Respectability of information inside perplexing cloud } \\
\text { facilitating situations, for example, Saas designed to impart } \\
\text { figuring asset among clients could give a risk against information } \\
\text { respectability if framework assets are viably isolated. }\end{array}$ \\
\hline \multicolumn{2}{|l|}{ Client access: } \\
\hline $\begin{array}{l}\text { - Poor character and access administration } \\
\text { Techniques. }\end{array}$ & $\begin{array}{l}\text { Execution of poor access control strategies makes numerous } \\
\text { danger opportunities for instance that displeased ex- } \\
\text { representatives of cloud supplier associations keep up remote } \\
\text { access to control client cloud benefits, and can result in } \\
\text { deliberate harm to their information sources. }\end{array}$ \\
\hline $\begin{array}{l}\text { Information quality: } \\
\text { • Introduction of broken application or foundation segments }\end{array}$ & $\begin{array}{l}\text { The danger of effect of information quality is expanded as } \\
\text { cloud suppliers host numerous clients' information. The } \\
\text { presentation of a broken or misconfigured segment needed by an } \\
\text { alternate cloud client could possibly sway the honesty of } \\
\text { information for other cloud clients offering foundation. }\end{array}$ \\
\hline \multicolumn{2}{|l|}{ Accessibility: } \\
\hline $\begin{array}{l}\text { Change administration: } \\
\text { - Customer infiltration testing affecting other cloud } \\
\text { clients } \\
\text { - Infrastructure changes upon cloud supplier, client } \\
\text { and outsider frameworks affecting cloud clients }\end{array}$ & $\begin{array}{l}\text { As the cloud supplier has expanding obligation for change } \\
\text { administration inside all cloud conveyance models, there is a } \\
\text { danger that progressions could present negative impacts. These } \\
\text { could be brought on by programming on the other hand fittings } \\
\text { changes to existing cloud administrations. }\end{array}$ \\
\hline \multicolumn{2}{|l|}{ Foreswearing of administration risk: } \\
\hline $\begin{array}{l}\text { The danger of disavowal of administration against accessible } \\
\text { cloud. } \\
\text { - Network transmission capacity circulated disavowal } \\
\text { of administration } \\
\text { - Network DNS refusal of administration }\end{array}$ & $\begin{array}{l}\text { Application and information refusal of administration } \\
\text { Processing asset is by and large an outer risk against open cloud } \\
\text { administrations. Nonetheless, the risk can affect all cloud } \\
\text { administration models as outer and inward risk executors could } \\
\text { present application or fittings segments that cause a foreswearing } \\
\text { of administration. }\end{array}$ \\
\hline \multicolumn{2}{|l|}{ Physical disturbance: } \\
\hline $\begin{array}{l}\text { - } \begin{array}{l}\text { Disruption of cloud supplier IT benefits through } \\
\text { physical access }\end{array} \\
\text { - Disruption of cloud client IT benefits through }\end{array}$ & $\begin{array}{l}\text { The risk of disturbance to cloud administrations created by } \\
\text { physical access is diverse between huge cloud administration } \\
\text { suppliers and their clients. These suppliers ought to be } \\
\text { accomplished in securing extensive server farm offices and have }\end{array}$ \\
\hline
\end{tabular}




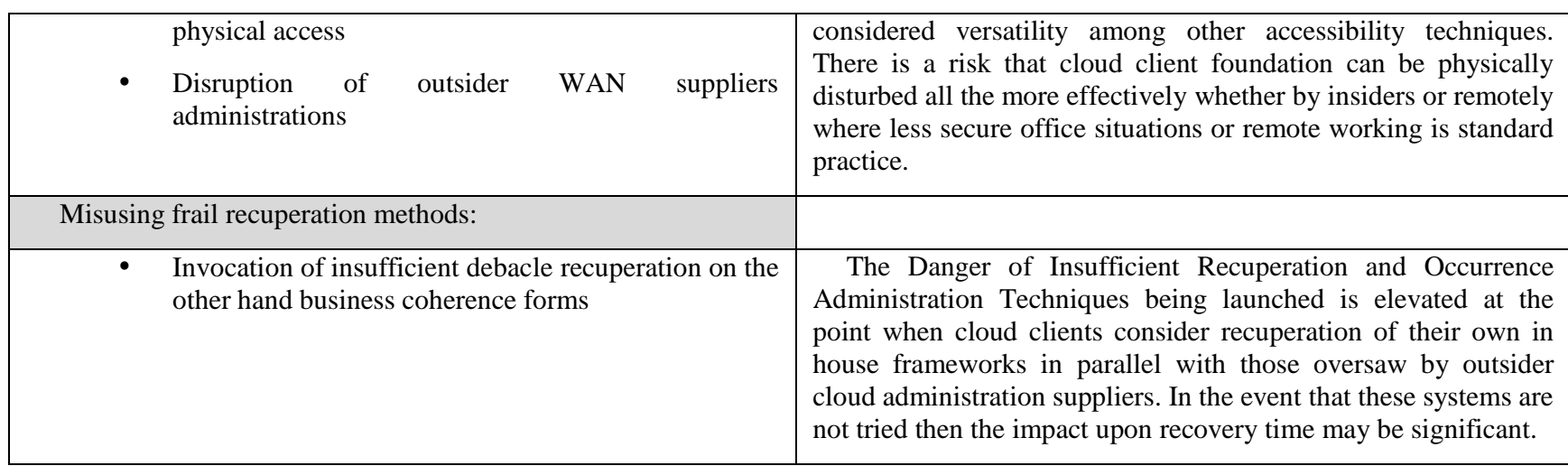

\section{TYPES OF ATTACKERS IN CLOUD COMPUTING}

Huge numbers of the security dangers and difficulties in distributed computing will be recognizable to associations overseeing in house foundation and those included in customary outsourcing models. Each of the cloud figuring administration conveyance models' dangers result from the assailants that can be isolated into two gatherings.

\section{Inward Assailants:}

An inward assailant has the accompanying qualities:

- Is utilized by the cloud administration supplier, client or other outsider supplier association supporting the operation of a cloud administration

- May have existing approved access to cloud administrations, client information or supporting base and applications, contingent upon their authoritative part

- Uses existing benefits to addition further get to or help outsiders in executing assaults against the secrecy respectability and accessibility of data inside the cloud administration.

\section{Outside Aggressors}

An outside aggressor has the accompanying qualities:

- Is not utilized by the cloud administration supplier, client or other outsider supplier association supporting the operation of a cloud administration

- Has no approved access to cloud administrations, client information or supporting framework and applications

- Exploits specialized, operational, methodology and social building vulnerabilities to assault a cloud administration supplier, client or outsider supporting association to addition further get to proliferate assaults against the classified, respectability furthermore accessibility of data inside the cloud administration. Albeit inside and outer assailants can be plainly separated, their capacity to execute effective assaults is the thing that separates them as a risk to clients and merchants much the same.

In the cloud environment, assailants can be sorted into four sorts: irregular, feeble, solid, and considerable (CPNI Security Briefing, 2010). Each of these classifications is focused around capacity to affect an effective assault, as opposed to on the kind of danger they show (i.e., criminal, surveillance or terrorism):

- Random- The most widely recognized kind of assailant uses straightforward devices and systems. The assailant may arbitrarily examine the Internet attempting to discover powerless parts. They will convey well known devices or procedures that ought to be effectively recognized.
- Weak - Weak - Semi-talented assailants focusing on particular servers/cloud suppliers by tweaking existing openly accessible instruments or particular targets. Their systems are more progressive as they endeavour to alter their assaults utilizing accessible endeavour devices.

- Strong - Organized generally financed and gifted gatherings of assailants with an inside order having some expertise in focusing on specific applications and clients of the cloud. For the most part this gathering will be a composed wrongdoing gathering gaining practical experience in vast scale assaults.

- Substantial- Motivated, solid aggressors not effortlessly caught by the associations they assault, or indeed by the applicable law requirement and investigative associations spend significant time in crime or digital security. Alleviating this danger obliges more noteworthy sagacity on assaults and authority assets in light of identification

\section{SOA FRAMEWORK MODEL}

The cloud structural planning depicted here permits us to build an exceptionally basic model of cloud security comprising of two fundamental ideas: a SOA security layer that lives on top of another Secure Virtualized Runtime layer. The Cloud Delivered Services layer is a perplexing, conveyed SOA environment. Distinctive administrations can be spread crosswise over diverse mists inside a venture. The administrations may be in distinctive regulatory or security spaces that interface together to structure a solitary cloud application. The SOA Security Model completely applies to the cloud. The Web Services (WS) convention stack structures the premise for SOA security and, in this Manner, principles based backing for spanning different security spaces to convey consistent client access to cloud administrations. This is particularly critical when entwining interior IT assets with outsider cloud administrations in a crossover cloud model, or when bundling a few outsider benefits in a marked offering to end clients.

One of the key parts of SOA is the capacity to effortlessly incorporate diverse administrations from distinctive suppliers. Distributed computing is pushing this model above and beyond than most endeavour SOA situations, since a cloud frequently underpins countless, administrations and benchmarks. This backing is given in an exceptionally dynamic and nimble style, and under extremely intricate trust connections. Specifically, a cloud SOA once in a while underpins a vast and open client populace, and it can't accept a pre-established relationship between cloud supplier and supporter.

Numerous cloud usage concentrate on particular conventions, for example, Open id for character league, and support particular compositional styles, for example, representational state exchange (REST).that endeavour class distributed 
computing must not farthest point its clients to a particular convention or style, yet rather, offer adaptability and decision. While IBM backings REST-based interfaces and conventions where fitting, SOA security needs the full scope of security administrations as portrayed in the SOA Security Reference Model.

\section{The Layers of a Typical Cloud Service}

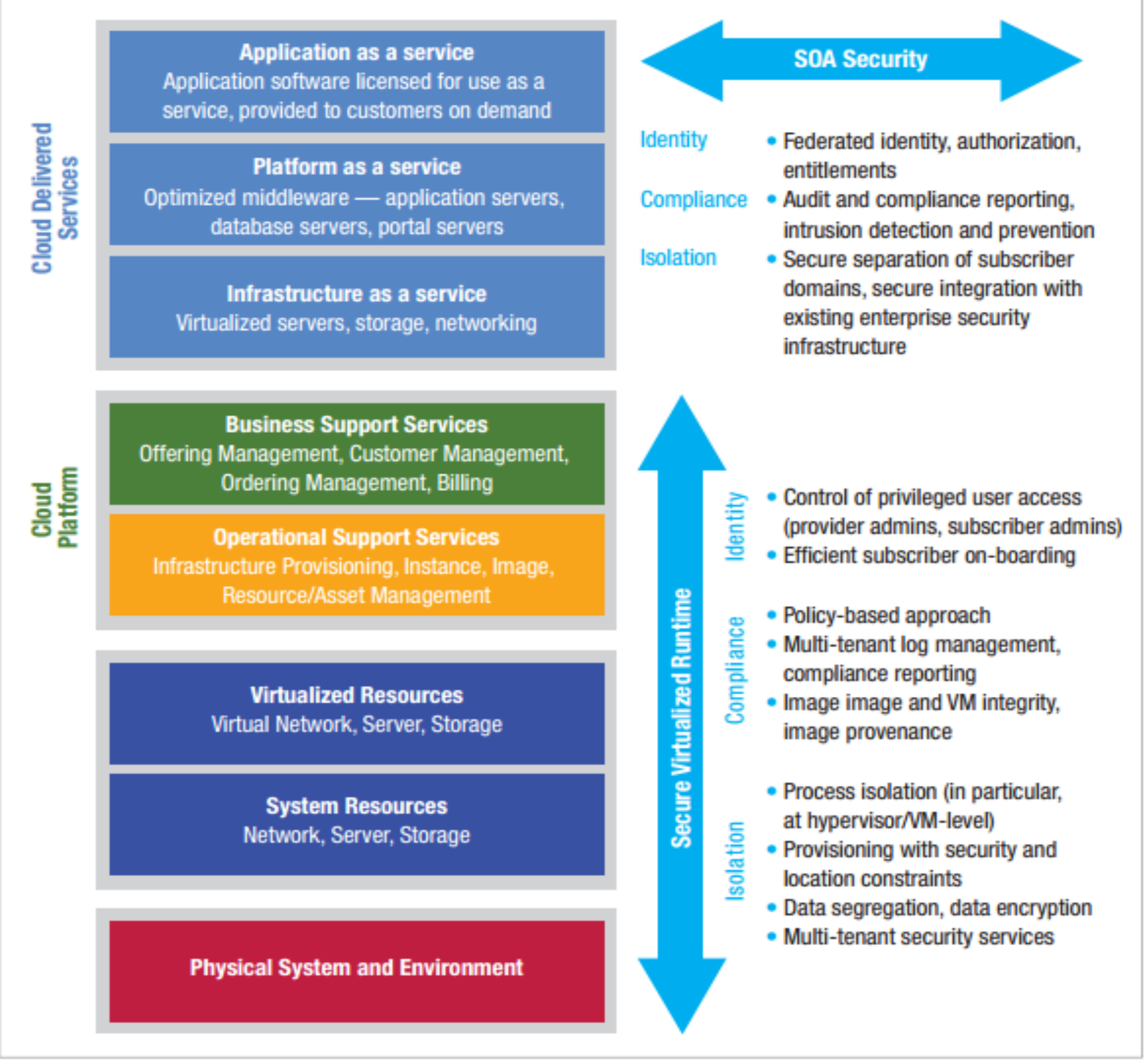

Figure 2. SOA Security Framework

Benchmarks based sealing, enlistment and verification of clients to cloud administrations speak to just the tip of the ice sheet for guaranteeing that the right clients have admittance to the right assets. Predictable approaches for qualifications and access control are expected to guarantee that all fundamental segments of a cloud administration keep up information secrecy and stick to agreeability regulations. Case in point, a medicinal examination application pulls information from clinical and charging administrations from numerous healing centres, so patient names and other by and by identifiable data must be expelled from all sources. An unified qualifications administration, in the same way as SOA Security Policy Manager, can help guarantee that regular approach is characterized and implemented to ensure understanding secrecy over all cloud administrations

\section{CONCLUSION AND FUTURE WORK}

Distributed computing is the fate of IT commercial ventures; it helps the businesses to get proficient utilization of their IT Hardware and Programming assets easily. This Paper Completely talks about the distributed computing security issues and Challenges. This paper additionally Dissect distributed computing vulnerabilities, security dangers distributed computing confronts and displayed the security objective that need to be attained. On one hand, the securitytouchy applications of a Cloud processing oblige high level of security then again, distributed computing are intrinsically defenceless against security assaults. Accordingly, there is a need to make them more secure and vigorous to adjust to the requesting necessities of these systems. The fate of distributed computing is truly engaging, giving the vision of modest 
interchanges. At present, the general pattern in cloud processing is to work structural engineering and huge scale. Change in transfer speed and limit is needed, which intimates the requirement for a higher recurrence and better spatial unearthly reuse. Huge scale distributed computing is an alternate testing issue within a brief period of time which can be now predicted.

\section{REFERENCES}

[1] "Cloud Computing: A Brief Summary Lucid Communications Limited”, Neil Turner September 2009.

[2] "Resource Management in Cloud Computing With Increasing Dataset", Preeti Agarwal, Yogesh Rathore by International Journal of Emerging Technology and Advanced Engineering June 2012.

[3] "Energy-Efficient Management of Data Center Resources for Cloud Computing", Cloud Computing and Distributed Systems (CLOUDS) Laboratory Department of Computer Science and Software Engineering The University of Melbourne, Australia.

[4] Y.T. Yu, M.F. Lau, "A comparison of MC/DC, MUMCUT and several other coverage criteria for logical decisions", Journal of Systems and Software, 2005, in press.

[5] "Mass Data Storage System for Campus Network Based on Cloud Computing", GaoXin_cheng, Li Chun_sheng.
[6] "Inter cloud Architecture and Application Brokering: Taxonomy and survey", Nikolay Grozev and Rajkumar Buyyaby Cloud Computing and Distributed System (CLOUDS) Laboratory, Department of Information system, The University of Melbourne VIC 3010 Australia.

[7] "An Overview and Study of Security Issues \& Challenges in Cloud Computing”, Rajesh Piplode Umesh Kumar Singh, International Journal of Advanced Research in Computer Science and Software Engineering Volume 2, Issue 9, September 2012.

[8] "Rackspace Cloud Monitoring Developer Guide", Rackspace Cloud Monitoring Application programming Interface (API) by Rackspace US March 11, 2014

[9] REST API: Zen desk Developers: REST API Documentation Zen desk Cloud Service Provider USA.

[10] "A Brief Guide to Cloud Computing: An Essential Introduction to the Next Revolution", Amazon USA.

[11] Oracle Database Cloud Service an Oracle White Paper May 2012.

[12] JaydipSen: Innovation Labs, Tata Consultancy Services Ltd., "Security and Privacy Issues in Cloud Computing" Kolkata, INDIA. 